\title{
PERFORMANCE STUDIES OF MICROBIAL FUEL CELL
}

\author{
Rakesh $^{1}$, Chandra ${ }^{2}$, Ujwal Shreenag Meda ${ }^{3}$, R. Suresh ${ }^{4}$ \\ ${ }^{I}$ Student, Department of Chemical Engineering, R.V. College of Engineering, Karnataka, India \\ ${ }^{2}$ Student, Department of Chemical Engineering, R.V. College of Engineering, Karnataka, India \\ ${ }^{3}$ Assistant Professor, Department of Chemical Engineering, R.V. College of Engineering, Karnataka, India \\ ${ }^{4}$ Professor and Head, Department of Chemical Engineering, R.V. College of Engineering, Karnataka, India
}

\begin{abstract}
Microbial fuel cells (MFCs) have gained a lot of attention in recent years for its ability to convert organic matter into electricity in the presence of microbes. Lot of research has been carried out on using wide range of substrates like acetate, glucose, monosaccharaides, domestic wastewater, industrial wastewater etc. Phenol and detergent are the major toxic components from industrial and domestic wastewater. If it is left untreated it can have detrimental effect on all kinds of aquatic life. In industries there are methods available for the treatment of these contaminants; however research on use of MFCs for treatment of these contaminants is still in infant stage. Using MFC will have a dual advantage of wastewater treatment as well as electricity generation. In this study a dual-chamber MFC was fabricated with a CMI 7000 membrane separating the chambers and carbon electrodes for both anode and cathode. Experiments were carried out to study the impact of microbes, type of substrate, substrate concentration and substrate refilling at regular intervals on voltage generated by MFC. Performance of MFC was studied by determining the voltage across $1 \mathrm{k} \Omega$ resistor. Furthermore, Industrial waste water from a local soap industry was used as a substrate along with the other substrates prepared in-house. Results showed that a stable voltage of around $134 m V$ can be obtained with phenol as substrate along with a mixed culture of pseudomonas aeruginosa and shewanella putrefaciens in comparison with all other combinations of substrates and microbes.
\end{abstract}

Keywords: Electricity generation, Microbial fuel cell, Pseudomonas aeruginosa, Shewanella putrefaciens, Waste water treatment and phenol degradation

\section{INTRODUCTION}

In recent decades, world energy consumption has a progressive trend. At present, this energy requirement is satisfied mostly by fossil fuels. Depletion of conventional energy sources and also its negative effect on environment has led many researchers to look for alternative energy sources. The new sources of energy should be renewable and also environmental-friendly. One of the renewable energy sources for the production of electricity is fuel cells (FC) [1]. Microbial fuel cells (MFCs) are a special type of FCs that have dual advantage. The microbes added convert organic matter into electricity and at the same time purify wastewater, thus may offset the operating costs of wastewater treatment plant [2]. An MFC is usually made of two chambers, anode and cathode. In anode chamber the organic material is oxidized by the microbes and the electrons are transferred to anode either by an added electron carrier or directly from the respiratory enzyme of the bacteria (mediator less) [3]. From anode electrons are transferred to cathode via external circuit, where electrons are consumed by terminal electron acceptors.

MFCs are technically still very far from attaining acceptable level of power output. However, with crucial advances in understanding the biological phenomena and substantial research in the engineering side such as cell architecture, materials and solution chemistry, considerable achievements in MFC performance have been achieved [4].
MFCs are being operated using a wide variety of substrates (fuels) which includes glucose, acetate, monosaccharaides and complex carbohydrates such as starch and biodegradable organics in food wastewater, swine wastewater and domestic wastewater as fuel [5]. The amount of electricity produced varies with different sources of fuel.

Industrial wastewater contains lot of toxic components which are being treated by various treatment technologies, but due to the problems associated with traditional chemical waste treatment systems, recent research has focused on the environmental application of microbes that have been isolated from their parent culture. These microbes help in degrading the organic pollutant present in the wastewater. Phenol is a very common effluent coming out of industries, including polymeric resin production, coal gasification, pharmacy, fertilizers and other chemicals [6]. Phenol can be toxic to aquatic organisms at a concentration beyond 5 $\mathrm{mg} / \mathrm{liter}$ and gives an objectionable taste to drinking water at far lower concentrations. Even at low temperatures these compounds are toxic and can cause unfavorable chemical changes in water and soil. Similarly, detergents the major component of domestic sewage can also have negative impact on aquatic life and adverse effect on treatment of waste water by producing lot of suds/froth. 
In this study, possibility of using MFC to treat waste water containing phenol and detergents using microbes such as pseudomonas aeruginosa and shewanella putrefaciens and to simultaneously generate electricity is explored.

\section{MATERIALS AND METHODS}

\subsection{Microbial Culture}

Media acts as source of food for the growth of microorganisms. The media prepared here was the nutrient agar media. The following constituents were added to prepare the media: yeast extract $(0.2 \mathrm{~g}), \mathrm{NaCl}(0.5 \mathrm{~g})$, beef extract $(0.1 \mathrm{~g})$, peptone $(0.5 \mathrm{~g})$. All these components were dissolved in distilled water using $100 \mathrm{~cm}^{3}$ volumetric flask. Later the content was transferred to a conical flask and the mouth of the conical flask was tightly closed with a cotton plug. The conical flask was covered with an aluminum foil and was kept for sterilization in an autoclave. Laminar air flow chamber (LAF) was used to prevent contamination during the transfer of microbes from mother culture to media. Surface of LAF chamber was wiped with $70 \%$ alcohol and the LAF was exposed to UV light for 20 minutes. Again the surface was wiped with $70 \%$ alcohol. The clear sterilized media which was prepared earlier as well as the pure culture of microbes were transferred into LAF chamber and blower was switched on. The pure culture of Pseudomonas aeruginosa was procured from microbiology department of Mangalore University. The nutrient broth media was inoculated with microbes from the petriplates using streaking method. After the microbes were transferred to the media, the conical flask was kept in the orbital shaker for 2-3 days. The clear solution of the media turned turbid indicating growth of microbes. It was stored in refrigerator at $12^{\circ} \mathrm{C}$ until it was used. Similarly Shewanella putrifaciens was also cultured.

\subsection{Buffer Preparation}

A pH of 7 should be maintained for the microbes to survive in the cell and phosphate buffer was used for this purpose. Phosphate buffer was prepared by mixing $30.5 \mathrm{ml}$ of $0.2 \mathrm{M}$ dibasic sodium phosphate with $19.5 \mathrm{ml}$ of $0.2 \mathrm{M}$ monobasic sodium phosphate. It was diluted to $100 \mathrm{ml}$ in a volumetric flask using double distilled water. The $\mathrm{pH}$ was checked using pH strip and was found to be 7 .

\subsection{Construction of MFC}

A dual chamber MFC as shown in figure 1 was fabricated using acrylic material, with thickness of $0.9 \mathrm{~cm}$, length $16 \mathrm{~cm}$ and width $14 \mathrm{~cm}$. The capacity of each chamber is 1.5 litres. Two chambers were separated using cationic exchange membrane (CMI-7000) with an area of $64 \mathrm{~cm}^{2}$. Electrode material used for both anode and cathode was carbon in the form of rods. The diameter of the carbon rod is $1.5 \mathrm{~cm}$ and length $5 \mathrm{~cm}$. 3 electrodes were hung in each chamber. An electrode spacing of $2.5 \mathrm{~cm}$ was maintained between anode and cathode. The measurement is between the outer surfaces of electrodes. The electrodes in the two chambers were connected externally using copper wire of cross section 1.5 $\mathrm{mm}^{2}$ with an external load consisting of $1000 \Omega$. A multimeter was used to measure the voltage across the resistor. Gasket and grease was used as sealant between the chambers and the lid to make the anode chamber air tight. Air was supplied externally to the cathode chamber using an aquarium air pump as the electrode is air cathode (proper supply of air is required).

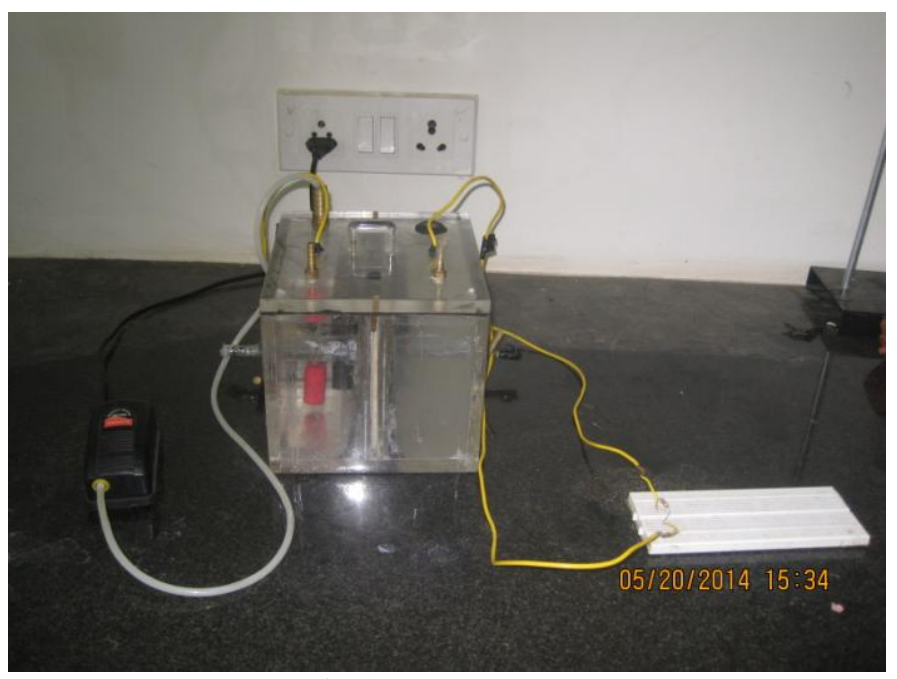

Fig-1: MFC Setup

\section{EXPERIMENTAL WORK}

Seven trials were carried out to determine parameters influencing the performance of MFC in terms of voltage such as microbes, substrate type, substrate concentration, substrate refilling and waste water from industry. In the beginning of every trial the entire setup was sterilized with isopropyl alcohol. The electrodes were immersed in $0.1 \mathrm{~N}$ $\mathrm{NaOH}$ and then in $0.1 \mathrm{~N} \mathrm{HCl}$ for almost a day using for experiments.

Trials: In the first trial $400 \mathrm{mg} / \mathrm{l}$ of phenol was prepared and used as substrate in anode chamber. Phosphate buffer was added to anode chamber in small quantities till the $\mathrm{pH}$ reached $7.15 \mathrm{ml}$ of pseudomonas aeruginosa culture was also added to the anode chamber. The cathode chamber was filled with distilled water. The fuel cell was closed using rubber gasket and grease Voltage was measured regularly across the load resistor using a multimeter. This experimental procedure was followed during all the trials carried out.

During second trial $15 \mathrm{ml}$ of shewanella putrefaciens was used and the experiment was carried out by keeping all other conditions the same.

In third trial a mixed culture containing $7.5 \mathrm{ml}$ of pseudomonas aeruginosa and $7.5 \mathrm{ml}$ of shewanella putrefaciens was added.

In fourth trial, 400mg/l detergent solution (prepared using surf excel washing powder) was used as substrate.

In the fifth trial a mixed substrate of $400 \mathrm{mg} / \mathrm{l}$ of phenol and $400 \mathrm{mg} / \mathrm{l}$ of detergent was used. 
In the sixth trial, a mixed substrate of $200 \mathrm{mg} / \mathrm{l}$ of phenol and $200 \mathrm{mg} / \mathrm{l}$ of detergent was taken.

In the last trail waste water stream from a local soap industry was used as substrate. $15 \mathrm{ml}$ of mixed culture containing pseudomonas aeruginosa and shewanella putrifaciens was used.

\section{RESULTS AND DISCUSSION}

Out of many parameters considered only a few were varied while the other parameters were fixed as follows.

Fixed parameters:

1. Electrode material: Carbon rods

2. Electrode spacing: $2.5 \mathrm{~cm}$ (between the outer surfaces)

3. Electrode area (anode : cathode) : 1:1

4. Concentration of Microbes

Variable parameters:

1. Substrate type: Phenol, detergent, mixed substrate (phenol + detergent), waste water from local soap industry

2. Type of Microbes: Pseudomonas, Shewanella, mixed culture (Pseudomonas + Shewanella)

3. Substrate concentration: 400mg/l (400mg/l, $200+$ $200 \mathrm{mg} / \mathrm{l}), 800 \mathrm{mg} / \mathrm{l}(400+400 \mathrm{mg} / \mathrm{l})$

Experiments were carried out by varying one parameter at a time. The potential difference between the electrodes was considered as the performance indicator.

\subsection{Effect of Microbes}

Based on literature and availability, two microbes were considered for the study of MFC performance. Three experiments were carried out, one with each of the microbes individually and the third one with both the microbes together as mixed culture. In all these experiments phenol was considered as substrate and concentration was fixed to $400 \mathrm{mg} / \mathrm{l}$.

From Fig-2 it is evident that Phenol-Pseudomonas combination reaches a peak voltage of $151.1 \mathrm{mV}$ within a day and the voltage decreases rapidly thereafter. A stable voltage was not obtained during the experiment that was conducted for 70 hours. In case of Shewanella the peak voltage obtained was $146.1 \mathrm{mV}$ and a stable voltage of $128.9 \mathrm{mV}$ was seen around 50 hours and remained fairly constant until the end of the experiment. With mixed microbial culture of pseudomonas and shewanella peak voltage of $150.8 \mathrm{mV}$ was observed and the voltage was stabilized around 60 hours. Mixed microbial culture seems to generate a higher value of stable voltage when compared to effect of the microbes individually. The reason for enhanced stability would be the use of mediators of one microbe by the other to transfer electrons to the electrode.

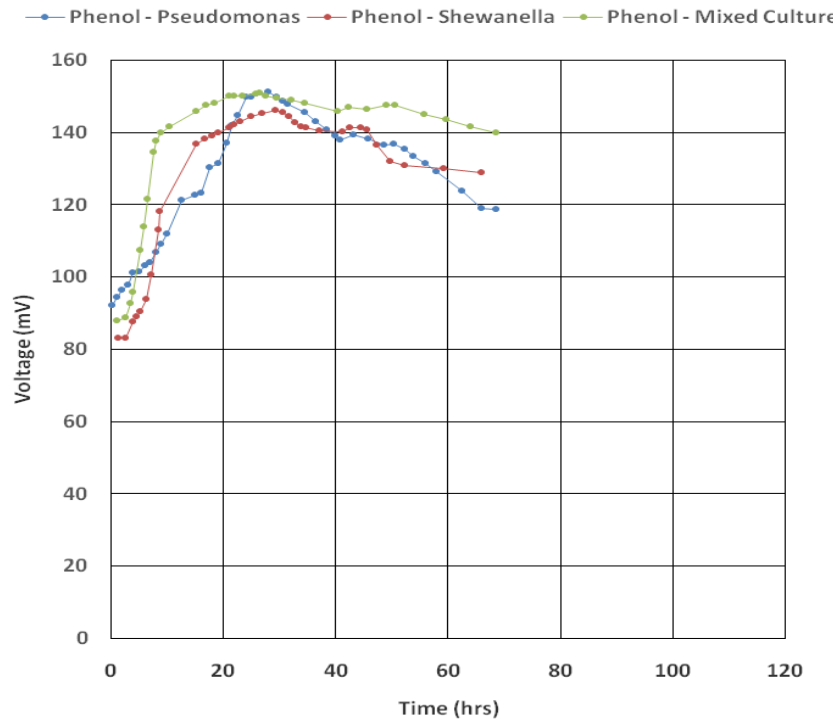

Fig-2: A plot of voltage generated $(\mathrm{mV})$ in a microbial fuel cell versus time (hours) with a concentration of $400 \mathrm{mg} / \mathrm{l}$ of phenol as substrate indicating the effect of microbes

\subsection{Effect of Substrate}

Phenol $(400 \mathrm{mg} / \mathrm{L})$, detergent $(400 \mathrm{mg} / \mathrm{L})$ and mixed substrate of phenol and detergent $(400+400 \mathrm{mg} / \mathrm{L})$ were used as substrates to study the effect of substrate on performance of MFC. A mixed microbial culture of Pseudomonas and Shewanella was used for these trials. From Fig-3 it is evident that phenol and mixed culture combination provides better and stable voltage than the rest of the combinations. With mixed substrate peak voltage value is decreased by $30 \mathrm{mV}$ and is stable around $94 \mathrm{mV}$. The reason for lower voltage value might be because of the formation of intermediate compounds which hinders the transfer of electrons to the electrode.

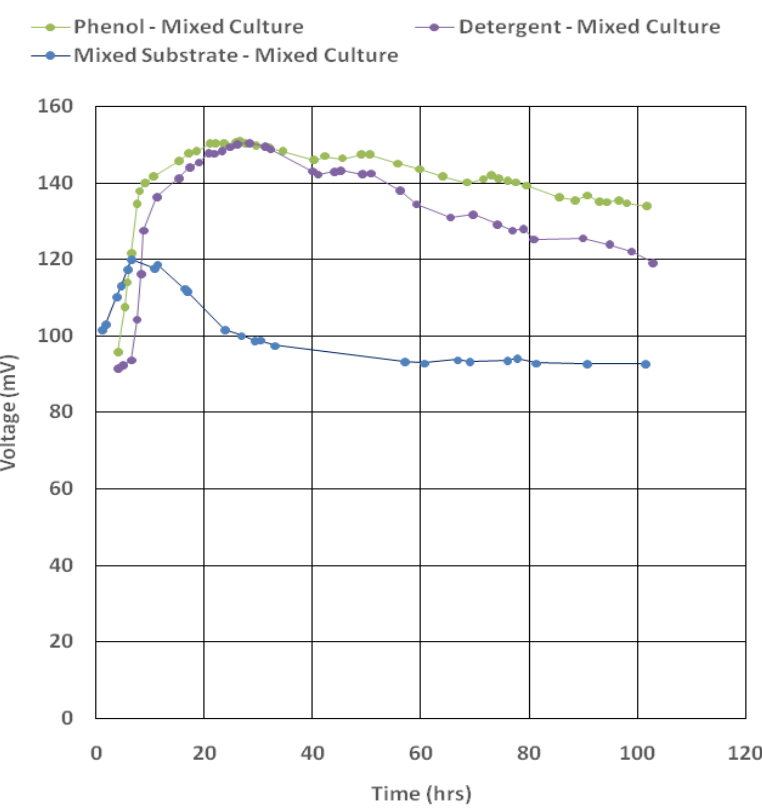

Fig-3: A plot of voltage generated $(\mathrm{mV})$ in a microbial fuel cell versus time (hours) with mixed microbial culture indicating the effect of various substrates 


\subsection{Effect of Substrate Concentration:}

A combination of mixed substrate of phenol and detergent and mixed microbial culture of Pseudomonas and Shewanella was used to study the effect of substrate concentration on performance of MFC. From Fig-4 it is evident that voltage is proportional to substrate concentration. Increase in substrate concentration leads to increase in voltage and voltage is fairly stable beyond 20 hours at both the concentrations that were tested. With both phenol and detergent concentrations at $400 \mathrm{mg} / \mathrm{L}$ a peak was obtained at $120 \mathrm{mV}$ and the voltage is stable around $94 \mathrm{mV}$. With concentration of phenol and detergent at $200 \mathrm{mg} / \mathrm{L} \mathrm{a}$ peak of $101 \mathrm{mV}$ was obtained the voltage is stable around $85 \mathrm{mV}$.

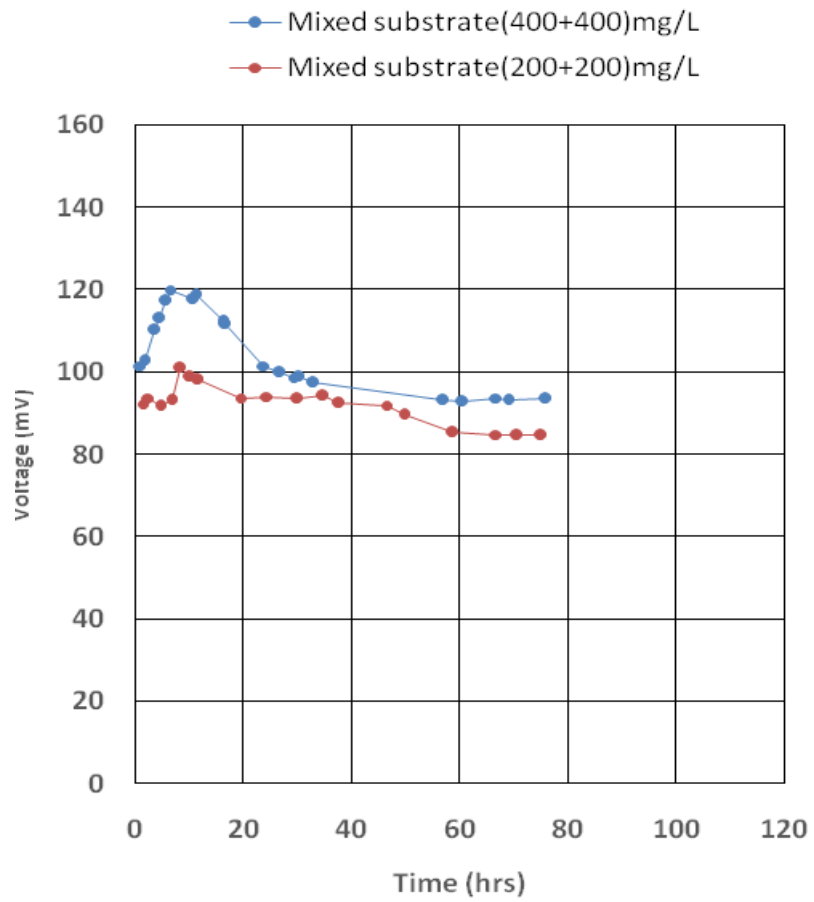

Fig-4: A plot of voltage generated $(\mathrm{mV})$ in a microbial fuel cell versus time (hours) with different concentrations of the mixed substrate

\subsection{Effect of Substrate Refilling}

An experiment that was carried out with phenol as substrate and mixed microbial culture of Pseudomonas and Shewanella. The experiment was further continued beyond $70 \mathrm{hrs}$ until $170 \mathrm{hrs}$ to determine the effect of substrate refilling. Fig-5 depicts that stable voltage can be drawn continuously by refilling the substrate at regular intervals. Substrate was refilled after $140 \mathrm{hrs}$ which is indicated by a red data point. The voltage that stabilized around 80 hours with a value of $134 \mathrm{mV}$ remained constant at that value even after refilling the substrate.

\subsection{Real Waste Water System:}

Industrial waste water (Karnataka soaps and detergents Ltd.), which mainly consists of detergent and soap waste was used as substrate for experiment with mixed microbial culture. Fig-6 illustrates the behavior of the real wastewater system. The results show that the voltage reached a stable value around $80 \mathrm{mV}$ after 30 hours.

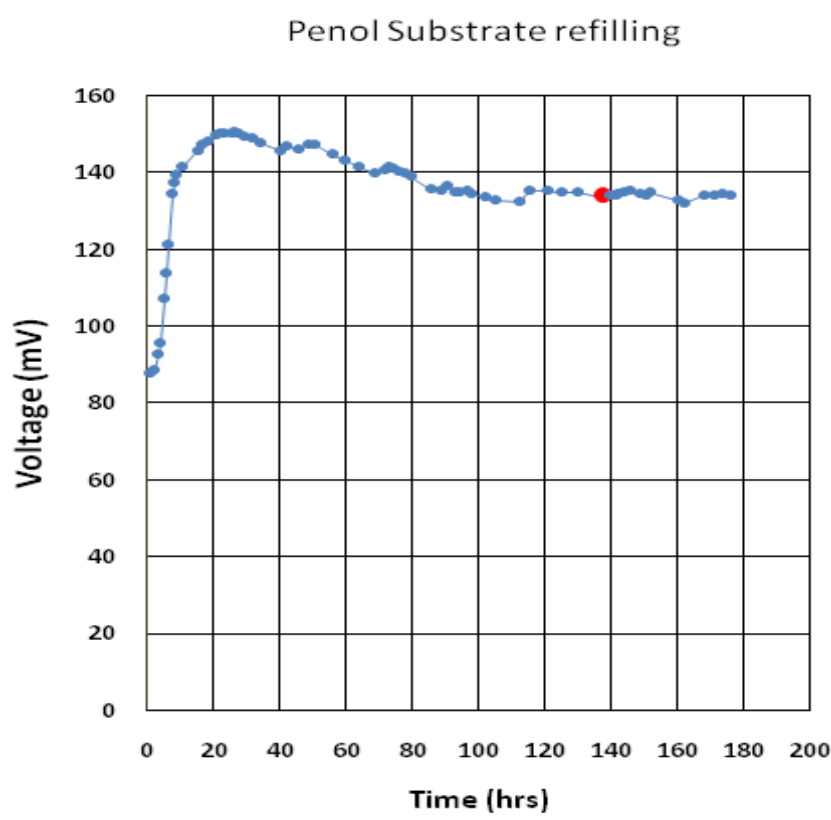

Fig-5: A plot of voltage generated $(\mathrm{mV})$ in a microbial fuel cell versus time (hours) with phenol substrate refilling

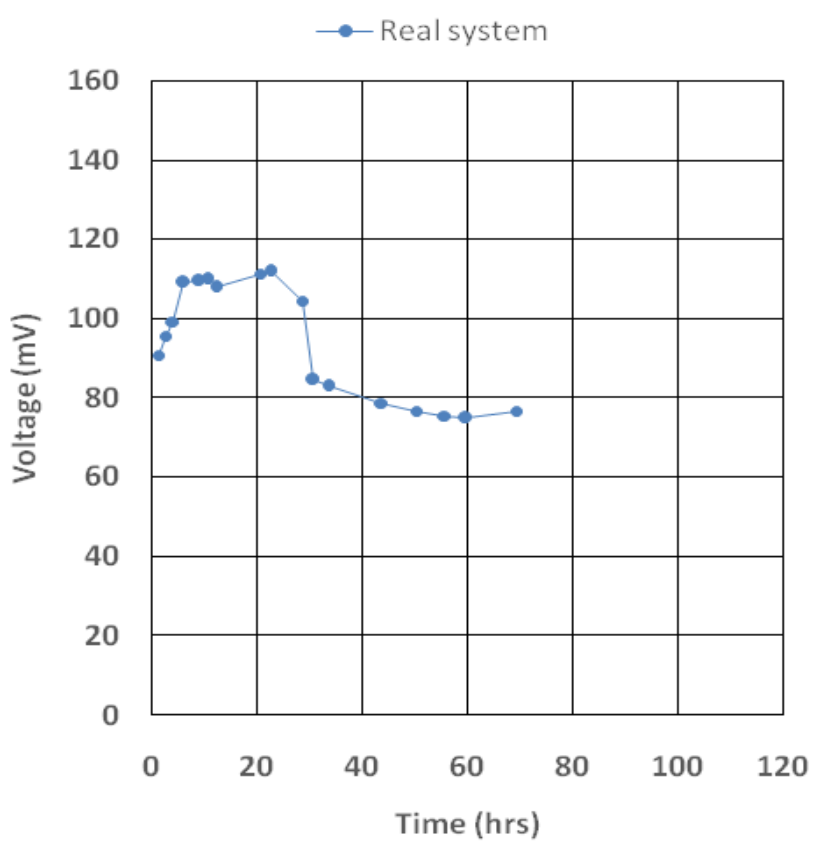

Fig-6: A plot of voltage generated $(\mathrm{mV})$ in a microbial fuel cell versus time (hours) with soap industry waste as substrate

\section{CONCLUSIONS}

According to the experiments carried out in a dual chamber fuel cell with carbon electrodes at both anode and cathode with $1 \mathrm{k} \Omega$ external load, conclusions on parameters influencing the performance of MFC in terms of voltage such as microbes, substrate, substrate concentration, substrate refilling and real system can be drawn as follows. 
Impact of microbes on voltage

A stable voltage of $134 \mathrm{mV}$ was obtained with phenol as substrate and a mixed culture of pseudomonas aeruginosa and shewanella putrefaciens.

- $\quad$ Voltage is stable in case of mixed culture microbes when compared with the individual microbes.

Impact of substrate on voltage

Better performance in terms of high and stable voltage was seen in case of phenol alone as a substrate when compared with detergent alone and a mixed substrate of phenol and detergent.

Impact of substrate concentration on voltage

Voltage increase with increase in substrate concentration.

- Voltage is directly proportional to the substrate concentration within a certain limit beyond which the environment turns unfavorable for microbial action.

\section{Substrate refilling}

Refilling substrate at regular intervals enables to withdraw stable voltage (in turn current) from fuel cell for longer durations

Real system (Industrial waste water)

A stable voltage of $76 \mathrm{mV}$ with a broad peak was obtained when waste water from soaps and detergents manufacturing industry was considered as substrate.

\section{FUTURE WORK}

1. Improvement in current MFC by trying with different electrode materials, electrode spacing, electrode area, membrane, catalysts and $\mathrm{pH}$.

2. Connecting multiple MFCs in series to draw higher voltages suitable for practical applications.

3. Development of a continuous system to draw current continuously.

4. Study on impact of intermediate products formed by mixing substrates on voltage generated.

\section{REFERENCES}

[1]. Mostafa Rahimnejad, Ali Asghar Ghoreyshi, Ghasem Najafpour, Tahereh Jafary, "Power generation from organic substrate in batch and continuous flow microbial fuel cell operations", Applied Energy, vol. 88, 2011, pp. 3999-4004. [2]. Lu, N., Zhou, S.G., Zhuang, L., Zhnag J.T., Ni J.R., "Electricity generation from starch processing wastewater using microbial fuel cell technology", Biochem. Eng. J, vol. 43, 2009, pp. 246-251.

[3]. Liu, H., Cheng, S., Logan, B.E., "Production of electricity from acetate or butyrate using a single chamber microbial fuel cell", Environ. Sci. Technol, vol. 39, 2005, pp. 658-662.

[4]. Rinaldi, A., Mecheri, B., Garavaglia, V., Licoccia, S., Nardo, P.D., Traversa, E., "Engineering materials and biology to boost performance of microbial fuel cells: a critical review", Energy Environ. Sci, vol. 1, 2008, pp. 417429.

[5]. Rabaey, K., Lissens G, Siciliano S D, Verstraete W., “A microbial fuel cell capable of converting glucose to electricity at high rate and efficiency", Biotechnol. Lett, vol. 25, 2003, pp. 1531-1535.

[6]. Haiping Luo, Guangli Liu, Renduo Zhang, Song Jin, "Phenol degradation in microbial fuel cells", Chemical Engineering Journal, vol.147, 2009, pp. 259-264.

[7]. Deepak Pant, Gilbert Van bogaert, Ludo Diels, Karolien Vanbroekhoven, "A review of the substrates used in microbial fuel cells (MFCs) for sustainable energy production", Bioresource technology, vol. 101, 2010, pp. 1533-1543.

[8]. Zhuwei, D.u., Haoran Li, TingyueGu, "A state of the art review on microbial fuel cells: A promising technology for wastewater treatment and bioenergy", Biotechnology Advances, vol. 25, 2007, pp. 464-482.

[9]. Yifeng Zhang, Booki Min, Liping Huang, Irini Angelidaki, "Electricity generation and microbial community response to substrate changes in microbial fuel cell”, Bioresource Technology, vol. 102, 2011, pp. 11661173.

[10]. Yogesh Sharma, Baikun Li, "The variation of power generation with organic substrates in single-chamber microbial fuel cells (SCMFCs )", Bioresource Technology, vol. 101, 2010, pp. 1844-1850.

[11]. Minghua Zhou, Meiling Chi, Jianmei Luo, Huanhuan He, Tao Jin, "An overview of electrode materials in microbial fuel cells", Journal of Power Sources, 2011, 44284437.

[12]. Sangeetha, T., Muthukumar, M., "Influence of Electrode Material and Electrode Distance on Bioelectricity Production from Sago-Processing Wastewater Using Microbial Fuel Cell" Environmental Progress \& Sustainable Energy, Vol.32, 2013, pp. 392-394.

[13]. Sourish Karmakar, Kanika Kundu and Subir Kundu, "Design and Development of Microbial Fuel cells, Technology and Education topics in applied microbial biotechnology" , A .Mendez- vilas(Ed), 2010, pp. 10311033.

\section{BIOGRAPHY}

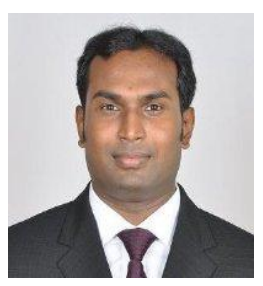

A Process Engineer with specialization in Process \& Product Design and experience in the field of Bulk Solids Handling, Powder Processing, Material Characterization, Food Emulsions, Emulsion Polymerization and Fuel cells. Over 6 years of academic and industrial work experience in multinational, multicultural and multilingual environment (dealing with clients from Germany, Belgium, Spain, Portugal, France, England and USA) 